\title{
38. Palynological Study of a 200-meter Core Sample from Lake Biwa, Central Japan. I
}

\author{
Palaeoclimate during the Last 600,000 Years
}

\author{
By Norio FuJ1*) and Shoji HoRIE**) \\ (Communicated by Teiichi KobAYASHI, M. J. A., March 12, 1977)
}

1. Introduction. Pollen analysis of the stratigraphic sequences in minute detail during the last two million years can reveal a continuous record of the change of vegetation and climate in the nonglaciated area. However, if a glacial eustatic theory is correct, it is difficult to collect continuous samples throughout the Quaternary in low land areas facing on the sea. Although sediments of both the cold and warm periods are complete in deep-sea cores, we can not evaluate changes in climate over short periods because of the extremely slow sedimentation rate. The following conditions need to be satisfied for the study of the palaeoclimate during the Quaternary in using the means of pollen analysis:

1) the rate of sedimentation must be "large",

2) the sediments must be entirely "fine-grained materials", and

3) sedimentation must be "continuous" since the early Pleistocene.

The bottom sediments of ancient lakes in unglaciated areas may cover the whole Pleistocene and Holocene. Lake Biwa in Japan is such a lake. Samples from a 200-meter core collected from a spot 65 meters deep at the bottom of Lake Biwa in 1971 have been used for the present palynological study.

In this paper, the palaeoclimate during the last 600,000 years based on the 200-meter core sample from Lake Biwa will be discussed from the viewpoint of pollen analysis.

2. Zoning of pollen assemblage. In order to facilitate the description and discussion of pollen assemblage, the 200-meter core is divided into 19 pollen zones based on conspicuous changes in pollen percentages.

3. Comparison with the previous climatic analyses and correlation of ages. Determination of the age with the use of the upper $11.5 \mathrm{~m}$ of the core obtained from Lake Biwa has been carried

\footnotetext{
*) Geological Institute, Faculty of Education, Kanazawa University.

**) Otsu Hydrobiological Station, University of Kyoto.
} 
out (Horie et al., 1971). Nishimura and Yokoyama (1975) presented invaluable data concerning the age-determination of the deeper part of the core through the fission-track method. And, ages (Kanari et al., 1975) throughout the core were determined by a suitable curvefitting method with the use of the basic data obtained from the abovementioned two methods. These estimated ages are not inconsistent with the data of the palaeomagnetic stratigraphy (Kawai et al., 1972) on the same core.

The lowermost horizon of the 200-meter core is dated as 565,000 years B.P. As we can find no comparable previous data of palynological study dealing with such remote antiquity and so long a duration of time as in the case of Lake Biwa, the writers correlated the diagram of Lake Biwa with Emiliani's palaeotemperature curve (1974) covering the last 700,000 years that was obtained from the Caribbean Sea on the basis of the oxygen isotope analysis.

On the palaeoclimatic curve by the writers, cold, warm, and temperate climatic periods are named respectively by such abbreviations as $c-1, c-2, \ldots ; \mathrm{w}-1, \mathrm{w}-2, \ldots$; and $t-1, t-2, \ldots$ from young to old period.

The t-10 period is correlated with no. 15 period of the Emiliani's curve. A short and more or less mild period is intercalated between c-10 and c-12 periods, and correlated with a milder period between nos. 13 and 14 of the Emiliani's curve. Although a cold period of the Emiliani's curve correlated with the c-12 period is no. 14, this cold period was short and colder than that of the c-12 period. A temperate climatic period shown by an abbreviation t-9 may be correlated with the Emiliani's no. 13 period.

Although the duration of the t-9 period is inferred to have been shorter than that of no. 13 period, this estimated duration results from a long interval sampling ( $5 \mathrm{~m}$ in interval). The $\mathrm{t}-8$ period is correlated clearly with no. 11 of the Emiliani's curve. In regard to the duration of this period, what has been stated about the $t-9$ period is also applicable.

Climatic fluctuations during the c-9 to c-7 periods are too indistinct to be correlated with any reasonable number of the Emiliani's curve. Especially, there are so many periods of mild climatic condition that it is difficult to find out clearly in the writers' curve. This is the case with a period to be correlated with the Emiliani's no. 9 . However, if the assumption that the c- 8 period correlated with a cold period between the Emiliani's no. 8 and no. 9 is correct, the t-7-b subperiod may be correlated with the Emiliani's no. 9. A temperate climatic period shown by an abbreviation t- 6 may be correlated with a cooler period just before no. 8 of the Emiliani's curve. It is most 


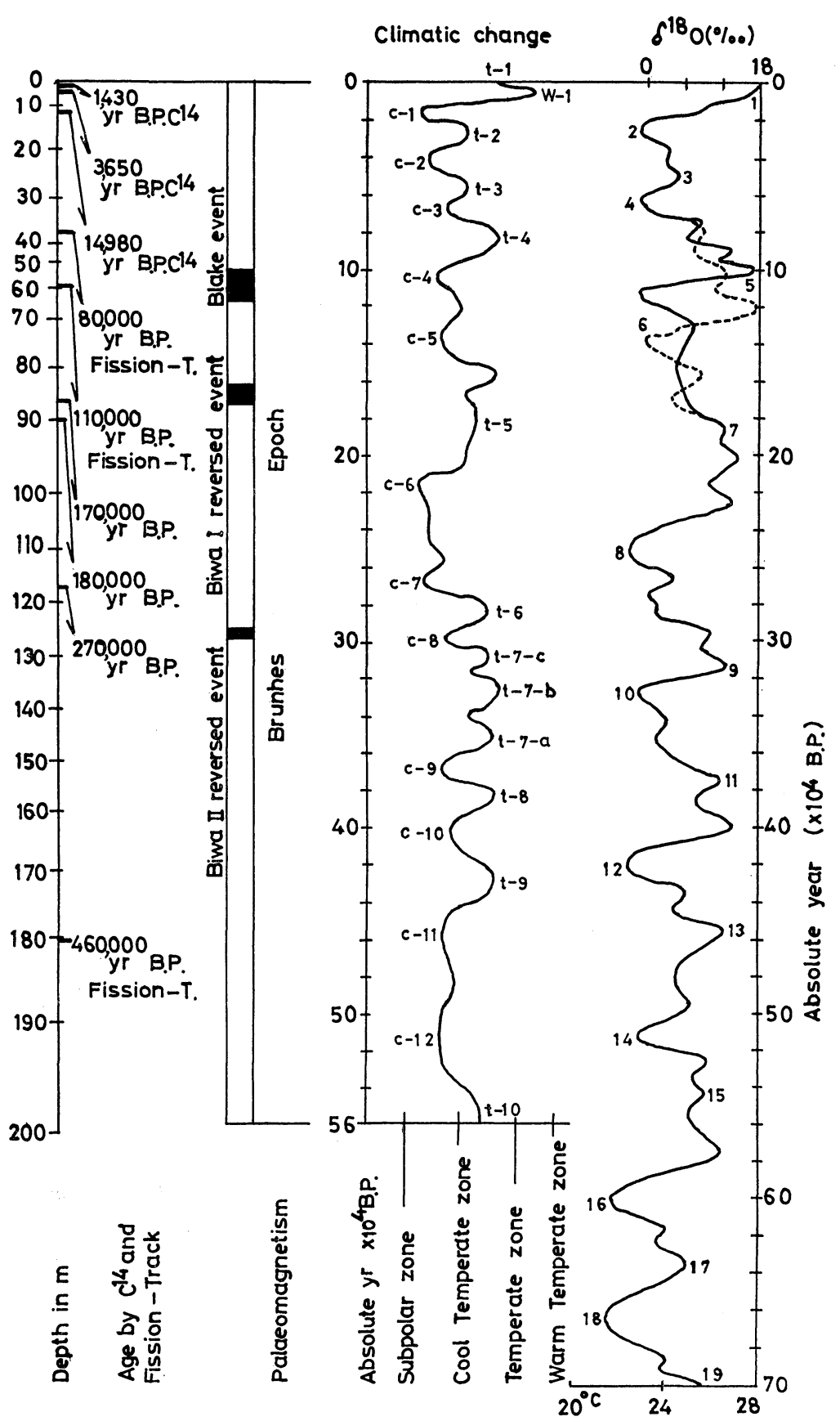

Fig. 1. Comparison between climatic change based on pollen analysis with absolute year estimated from Lake Biwa and Emiliani's general palaeotemperature curve (1974) based on oxygen isotope analysis from the Caribbean Sea since about 600,000 years B.P. 
probable that the cold c-7 and mild t-5 periods are correlated with the Emiliani's no. 8 and no. 7 respectively. The climatic condition in the interval from c-7 period to c-6 period was a continuous cold climate, and a drastic climatic amelioration is recognized in the interval (about 210,000 years B.P.) between the c-6 and t-5 periods. In contrast to the fact mentioned just above, a drastic climatic amelioration is recognized at the time (the Emiliani's no. 8 to no. 7) corresponding to the age between the c-7 and c-6. By two tentative curves, Emiliani (1974) showed the change of palaeotemperature during the age between the mild no. 7 and cold no. 4 periods. According to the writers' analysis, the climatic change during the same age may closely correspond to the trend of the Emiliani's dotted curve (Fig. 1). The c-3, t-3, c-1, and t-1 periods may correspond to the Emiliani's nos. 4, 3 and 1 periods respectively from the viewpoint of climate.

Judging from the detailed absolute chronology and palaeoclimatology, a few differences are recognized between the Emiliani's generalized temperature curve from the Caribbean Sea and the writers' climatic curve from Lake Biwa. In spite of such differences in details and in interpretation of curves, however, similarity about the climatic curve and absolute age exists between the major trends of the two from the viewpoint of palaeoclimatic evidences.

\section{References}

Emiliani, C., and N. J. Shackleton (1974) : Science, 183, 511.

Fuji, N., and S. Horie (1972): Proc. Japan Acad., 48, 500.

Fuji, N. (1973) : Proc. Japan Acad., 49, 737.

Horie, S., O. Mitamura, S. Kanari, A. Yamamoto, and N. Fuji (1971): Disaster Prev. Res. Inst. Kyoto Univ., Annuals (B), 14, 745.

Kanari, S., and Y. Takenoya (1975): Paleolimnology of Lake Biwa and the Japanese Pleistocene., 3 (ed. S. Horie), 235.

Kawai, N., K. Yaskawa, T. Nakajima, M. Torii, and S. Horie (1972): Proc. Japan Acad., 48, 186.

Nishimura, S., and T. Yokoyama (1975): Paleolimnology of Lake Biwa and the Japanese Pleistocene., 3 (ed. S. Horie), 138. 